\title{
PATIENTS ON THE WAITING LIST OF A LONDON TEACHING HOSPITAL
}

\author{
J. F. BITHELL, M.A., D.Phil. \\ Department of Biomathematics, University of Oxford*
}

This paper is the second to result from a one-year study at St. Thomas' Hospital, London conducted in 1965-6, a full report of which study (Bithell, 1968) has been presented to the Governors of the Hospital.

Any study of hospital waiting lists needs to distinguish carefully between statistics relating to patients on a waiting list at any time and those relating to patients admitted to or taken off the waiting list in a given period. For example, a sample of patients on a waiting list at a particular time will generally yield a different distribution of waiting times from that of patients leaving the list (for admission or otherwise) over a given period. This is because in the former case the patients have not completed their term of waiting and because, in addition, the longer such patients wait, the higher their chance of being included in the sample. (In some circumstances the one distribution may be estimated from the other, but the process is not straightforward and it is preferable to collect the data appropriate to the enquiry in hand.)

Simple counts of waiting list lengths are of the former, 'list-oriented' type. The St. Thomas' study, however, was mainly based on 'patient oriented' information (Bithell, 1969a) and this has resulted in analyses largely geared to the experiences of patients actually admitted to the hospital or removed from the waiting list. For this reason, the majority of this paper is concerned with information on the patients: only the next section refers to the actual sizes of the lists observed. Some organizational points are discussed in the last section.

Warting List Lengths-General Picture

Table I shows the waiting lists for certain specialties at the end of the study period (March 1966). The total excludes private, maternity, and gynaecology patients, who did not feature in the study, and also orthopaedics, for the reasons discussed below.

Originally it was intended to study the lists through time by adding and subtracting admissions

\footnotetext{
Present address: Department of Social Medicine, University of Oxford.
}

TABLE I

WAITING LIST AND WAITING TIME STATISTICS BY SPECIALTY

\begin{tabular}{|c|c|c|c|c|c|}
\hline \multirow{2}{*}{ Specialty } & \multirow{2}{*}{$\begin{array}{c}\text { No. on } \\
\text { W/L } \\
\text { March } \\
1966\end{array}$} & \multicolumn{3}{|c|}{ Waiting Time (days) } & \multirow{2}{*}{$\begin{array}{l}\text { No. of } \\
\text { Cases }\end{array}$} \\
\hline & & Mean & S.D. & Median' & \\
\hline $\begin{array}{l}\text { Gen. medicine } \\
\text { Gen. surgery } \\
\text { Paediatrics } \\
\text { Neurology } \\
\text { Cardiology } \\
\text { E.N.T. } \\
\text { Ophthalmology } \\
\text { Plastic surgery } \\
\text { Orthopaedics }\end{array}$ & $\begin{array}{r}80 \\
750 \\
7 \\
24 \\
36 \\
589 \\
61 \\
130 \\
-2\end{array}$ & $\begin{array}{r}32 \\
65 \\
28 \\
29 \\
80 \\
65 \\
48 \\
206 \\
83\end{array}$ & $\begin{array}{r}53 \\
93 \\
44 \\
33 \\
67 \\
70 \\
61 \\
255 \\
144\end{array}$ & $\begin{array}{r}15 \\
30 \\
15 \\
17 \\
67 \\
43 \\
26 \\
108 \\
36\end{array}$ & $\begin{array}{r}655 \\
2,312 \\
95 \\
217 \\
134 \\
937 \\
382 \\
177 \\
353\end{array}$ \\
\hline $\begin{array}{l}\text { All male } \\
\text { All female }\end{array}$ & $\begin{array}{r}1,005 \\
783\end{array}$ & $\begin{array}{l}61 \\
61\end{array}$ & $\begin{array}{r}88 \\
108\end{array}$ & $\begin{array}{l}30 \\
26\end{array}$ & $\begin{array}{l}3,209 \\
2,781\end{array}$ \\
\hline All & 1,788 & $61 \cdot 4$ & 98 & 28 & 5,990 \\
\hline
\end{tabular}

${ }^{1}$ Estimated from frequency distributions

'See text

and new cases, but the method is unsatisfactory as it is liable to be upset by under-reporting of the removal of cases placed on the list before the study started. Moreover, the very execution of the study is likely to affect the extent to which waiting lists are periodically reviewed and pruned. (Grundy, Hitchins, and Lewis-Faning (1956) noticed a dramatic reduction of the lists in the period of their detailed study of Cardiff hospitals.)

It is well known that many waiting lists contain considerable numbers of patients who will quite probably never be admitted to the hospital concerned. At St. Thomas' this was best exemplified by the orthopaedic specialty, in which list nearly 500 names were recorded. Consideration of the new patient rate and the average waiting time suggested that the effective list was only two-fifths of the whole and that it was superimposed on a pool of patients of some years' standing with no immediate prospect of admission. Precise figures were impossible to determine, however; as one list served all the hospitals in the Group, it was not clear which patients would be admitted to which hospital and the estimates necessarily relate to the Group as a whole.

General considerations in the management of waiting lists will be further discussed in the final 
section. Quite apart from problems of accuracy, crude list lengths, taken without reference to the admission rates, are a poor guide to the size of the waiting list problem; a better measure is provided by the waiting times, discussed in the next section.

\section{WaITING Times}

Table I also shows the basic statistics on waiting time distributions for different specialties. The times exhibited no important differences between sexes. Plastic surgery patients clearly had to wait the longest-almost seven months on average. On the list as a whole, however, only half the patients had to wait over one month. The mean waiting time was 61 days, which compares favourably with the picture for the country as a whole: the figures in the Hospital In-Patient Enquiry for 1966 (Ministry of Health and General Register Office, 1968), using diagnostic frequencies as weights, gave an average of 85 days.

Table II gives the mean waiting times for different age groups, and it is clear that there is a pronounced inverse relationship, children waiting longer and

TABLE II

MEAN WAITING TIMES TO ADMISSION BY AGE

\begin{tabular}{l|ccccc|c}
\hline & \multicolumn{6}{|c}{ Age (years) } \\
\cline { 2 - 7 } Waiting Time (days) & $0-4$ & $5-14$ & $15-44$ & $45-64$ & $65+$ & All \\
\hline $\begin{array}{l}\text { Mean } \\
\pm \text { S.E. }\end{array}$ & $77 \cdot 2$ & $71 \cdot 8$ & $68 \cdot 6$ & $52 \cdot 5$ & $50 \cdot 5$ & $61 \cdot 4$ \\
$\pm 4 \cdot 2$ & $\pm 3 \cdot 3$ & $\pm 2 \cdot 6$ & $\pm 1 \cdot 8$ & $\pm 2 \cdot 9$ & $\pm 1 \cdot 3$ \\
\hline No. of cases & 386 & 633 & 2,043 & 2,098 & 830 & 5,990 \\
\hline
\end{tabular}

older patients being admitted more quickly. Examinations of the correlations within specialties indicated that the effect was most marked in Cardiology, E.N.T., and Plastic Surgery. The relationship does not hold uniformly throughout the diagnostic categories, as the selection in Table III shows; however, it seems likely that, in at least some groups, age is in itself an inducement to a consultant to expedite admission.

\section{Patients Faillng to Arrive}

Details of the first letter (or other communication) sent to each waiting list patient were recorded and an analysis of the results is presented in Table IV. Altogether some $12.6 \%$ of patients failed to arrive

TABLE IV

REASONS FOR NON-ADMISSION AFTER FIRST COMMUNICATION

\begin{tabular}{|c|c|c|c|}
\hline Reasons for Non-arrival & Male & Female & Total \\
\hline $\begin{array}{l}\text { Too short notice given } \\
\text { Prevented by commitments } \\
\text { Too ill other causes } \\
\text { Treated elsewhere } \\
\text { Other and unknown }\end{array}$ & \multicolumn{2}{|c|}{$\begin{array}{rc}\text { (\% of non-arrivals } \\
6.1 & 6.4 \\
27.0 & 27.3 \\
10.2 & 14.5 \\
4.9 & 2.5 \\
51.8 & 49.3\end{array}$} & $\begin{array}{r}6 \cdot 2 \\
27 \cdot 1 \\
12 \cdot 0 \\
3 \cdot 9 \\
50 \cdot 8\end{array}$ \\
\hline Total $\quad(\%)$ & $100 \cdot 0$ & $100 \cdot 0$ & $100 \cdot 0$ \\
\hline $\begin{array}{l}\text { Non-arrivals } \int \text { (cases) } \\
\text { Accepted and came }\end{array}$ & $\begin{array}{r}411 \\
2,527\end{array}$ & 2,282 & $\begin{array}{r}693 \\
4,825\end{array}$ \\
\hline Total & 2,938 & 2,580 & 5,518 \\
\hline$\%$ not arriving & $14 \cdot 0$ & 10.9 & $12 \cdot 6$ \\
\hline
\end{tabular}

when notified but it was possible to find an adequate reason in only about half of these cases.

In studying the effects on non-arrival rates of various factors, it is natural to compare the results with the recent comprehensive study by Morris, Hall, and Handyside (1969) of six months' admissions from surgical waiting lists at King's Mill Hospital. In contrast to their findings, males showed a significantly higher rate $(14.0 \%)$ than females $(10.9 \%)$ in the St. Thomas' study. Age had comparatively little effect, although a high proportion $(4.8 \%)$ of children under 15 were recorded as 'too ill from other causes' (as opposed to $1.0 \%$ of all adults).

As in the King's Mill study, there was no appreciable seasonal variation in the non-arrival rate and even the increase to $18.7 \%$ for admissions requested over 17 days of the Easter, Whit, summer, and Christmas holidays was not significant. This was clearly because the numbers of admission requests were sharply lower-at 5.4 per day instead

TABLE III

MEAN WAITING TIMES (WITH STANDARD ERRORS) BY AGE GROUP FOR SELECTED DIAGNOSES (IN DAYS)

\begin{tabular}{|c|c|c|c|c|c|c|c|c|}
\hline \multirow[b]{2}{*}{ Diagnosis } & & \multicolumn{3}{|c|}{ Age $15-44$ yr } & \multicolumn{3}{|c|}{ Age 45-64 yr } & \multirow{2}{*}{$\frac{\text { Difference }}{\text { S.E. }}$} \\
\hline & & Mean & S.E. & $\begin{array}{l}\text { No. of } \\
\text { Cases }\end{array}$ & Mean & S.E. & $\begin{array}{r}\text { No. of } \\
\text { Cases }\end{array}$ & \\
\hline $\begin{array}{l}\text { Benign neoplasm (excluding breast, CNS) } \\
\text { Disease of ear and mastoid processes } \\
\text { Hernia of abdominal cavity } \\
\text { Disease of urinary system }\end{array}$ & $\begin{array}{l}\mathbf{M} \\
\mathbf{F} \\
\mathbf{M} \\
\mathbf{F} \\
\mathbf{M} \\
\mathbf{F} \\
\mathbf{M}\end{array}$ & $\begin{array}{l}50.1 \\
65.7 \\
72.7 \\
67.0 \text { 土 } \\
90.0 \pm \\
53.4 \pm \\
51.0 \text { 圭 } \\
42.4 \pm\end{array}$ & $\begin{array}{r}8 \cdot 3 \\
12 \cdot 3 \\
16 \cdot 6 \\
8 \cdot 9 \\
18 \cdot 8 \\
13 \cdot 5 \\
9 \cdot 6 \\
8 \cdot 7\end{array}$ & $\begin{array}{r}42 \\
32 \\
42 \\
65 \\
60 \\
9 \\
48 \\
39\end{array}$ & 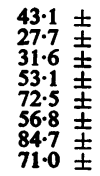 & $\begin{array}{r}6 \cdot 6 \\
5 \cdot 9 \\
3 \cdot 5 \\
10 \cdot 3 \\
11 \cdot 7 \\
10 \cdot 5 \\
19 \cdot 9 \\
13 \cdot 8\end{array}$ & $\begin{array}{l}82 \\
51 \\
32 \\
42 \\
87 \\
25 \\
44 \\
38\end{array}$ & $\begin{array}{r}0.66 \\
2.78 \\
2.42 \\
1.02 \\
0.79 \\
-0.20 \\
-1.53 \\
-1.75\end{array}$ \\
\hline
\end{tabular}


of 15.5-whereas the numbers sent for by King's Mill showed no drop in the fortnight of factory holidays (see Table III of Morris et al., 1969). Unlike the holiday periods, the New Year week (beginning December 28) at St. Thomas' Hospital had high notification rates averaging 23 per day, presumably to compensate for the Christmas run-down; nonarrival rates in this period were low, at $8.7 \%$.

It was not feasible to examine differences in nonarrival rates between consultants, as there was considerable sharing of responsibility within firms. Among specialties, E.N.T. had appreciably the worst rate, with an especially high number of admissions 'prevented by commitments'; altogether $16 \%$ of these cases failed to come after the first communication.

As expected, the method of notification was found to be an important factor. Of the 241 patients first summoned by telephone or telegram, only 11 $(4.4 \%)$ failed to come, in contrast to $12.7 \%$ of those who were sent a letter.

It is interesting to examine the amount of notice given in the first communication calculated by subtracting the dates, and ignoring complications of postal delivery time. Comparison of the columns of Table V shows that those patients who complained of 'too short notice' did indeed have significantly less notice than those who came, the mode being at two instead of three days, and the mean being around two days less.

There was a strong association between acceptance and time to the first letter; for those who accepted and arrived the mean waiting time was $53.9( \pm 1.2)$ days, while for those who failed to arrive it was 75.1 ( \pm 3.8$)$ days. Moreover, the association persisted within the broad age groups shown in Table II and seems unlikely, therefore, to be due solely to the association with age already discussed above. However, patients who cannot accept the first offer of a bed necessarily spend longer on the waiting list; to disentangle cause and effect it would be necessary to analyse response to subsequent communications in some detail.

\section{Booked Cases}

The Hospital In-Patient Enquiry defines a booked case as one given an admission date 'as soon as the necessity for in-patient treatment has been determined'. This is not as watertight as it may appear to be, as such a date may have to be altered subsequently, or the patient may be admitted as an emergency in the meantime. Even if the booked date is adhered to, it is possible that it was originally given only provisionally and subsequently confirmed. (Around $75 \%$ of cases marked 'booked' at admission received reminder communications.) This problem makes comparisons between booked and unbooked cases rather difficult.

Altogether there were 616 cases marked as 'booked' on arrival at St. Thomas' in the study year, i.e., $5.5 \%$ of all admissions. (This compares with $2.6 \%$ to the United Oxford Hospitals (Radcliffe Infirmary and Churchill Hospital) for 1963-5, for example.1) Of those with known booking dates, $94 \%$ arrived on the right day. Their mean time to admission was 16 days, compared with 56 days for all other cases.

\section{Patients Removed From the WaIting List}

Some 527 patients were recorded as having been removed from the waiting list during the study year, although this could be an under-estimate, as discussed above. Table VI analyses the reasons given for removal and it will be seen that the majority were treated elsewhere. Of these, $85 \%$ were treated at other hospitals in the Group.

IFigures from the Oxford Record Linkage Study.

TABLE V

AMOUNT OF NOTICB GIVBN TO WAITING LIST CASES (FIRST COMMUNICATION)

\begin{tabular}{|c|c|c|c|c|c|c|}
\hline \multicolumn{2}{|c|}{ Amount of Notice } & \multirow{2}{*}{$\begin{array}{r}\text { Too Short Notice } \\
1 \\
1 \\
15 \\
10 \\
8 \\
3 \\
1 \\
1\end{array}$} & \multirow{2}{*}{$\begin{array}{c}\begin{array}{c}\text { Failed to Come } \\
\text { (any reason) }\end{array} \\
2 \\
17 \\
63 \\
148 \\
121 \\
96 \\
65 \\
56\end{array}$} & \multirow{2}{*}{$\begin{array}{c}\text { Accepted and Came } \\
99 \\
138 \\
547 \\
1,132 \\
829 \\
612 \\
509 \\
330\end{array}$} & \multirow{2}{*}{$\begin{array}{c}\text { Over-all (\%) } \\
0 \cdot 2 \\
2 \cdot 8 \\
11 \cdot 1 \\
23 \cdot 2 \\
17 \cdot 2 \\
12 \cdot 8 \\
10 \cdot 4 \\
7 \cdot 0\end{array}$} & \multirow{2}{*}{$\begin{array}{c}\% \text { Not Arriving } \\
18.2 \\
11.0 \\
10 \cdot 3 \\
11.6 \\
12.7 \\
13 \cdot 6 \\
11 \cdot 3 \\
14.5\end{array}$} \\
\hline Days & $\begin{array}{l}0 \\
1 \\
2 \\
3 \\
4 \\
5 \\
6 \\
7\end{array}$ & & & & & \\
\hline Weeks & $\begin{array}{l}1-2 \\
2+\end{array}$ & $\begin{array}{l}2 \\
1\end{array}$ & $\begin{array}{l}84 \\
41\end{array}$ & $\begin{array}{l}512 \\
207\end{array}$ & $\begin{array}{r}10.8 \\
4.5\end{array}$ & $\begin{array}{l}14 \cdot 1 \\
16.5\end{array}$ \\
\hline $\begin{array}{l}\text { All } \\
\text { Mean (d } \\
\pm \text { Stand }\end{array}$ & derror & $\begin{array}{c}43 \\
3 \cdot 8 \\
0-49\end{array}$ & $\begin{array}{c}693 \\
6.1 \\
0.26\end{array}$ & $\begin{array}{c}, 825 \\
5.9 \\
0.15\end{array}$ & $\begin{array}{c}100-0 \\
5.9 \\
0.13\end{array}$ & $\begin{array}{l}12 \cdot 6 \\
=\end{array}$ \\
\hline
\end{tabular}


TABle VI

REASONS FOR REMOVAL FROM THE WAITING LIST

\begin{tabular}{|c|c|c|c|}
\hline \multirow{2}{*}{$\begin{array}{l}\text { Reason } \\
\text { Treated elsewhere } \\
\text { No reply/gone away } \\
\text { Dead } \\
\text { No further need } \\
\text { No further wish } \\
\text { Other reasons }\end{array}$} & \multicolumn{3}{|c|}{$\begin{array}{l}\text { Male Female Total } \\
\text { (\% of all removals) }\end{array}$} \\
\hline & $\begin{array}{r}71.5 \\
3.8 \\
2.2 \\
6.6 \\
5.1 \\
10.8\end{array}$ & $\begin{array}{r}71.1 \\
1.4 \\
1.4 \\
6.1 \\
5.7 \\
14.2\end{array}$ & $\begin{array}{r}71.3 \\
2.8 \\
1.9 \\
6.5 \\
5.3 \\
12.1\end{array}$ \\
\hline $\begin{array}{l}\text { Total } \\
\text { Cases removed } \\
\% \text { of all cases taken off }\end{array}$ & $\begin{array}{l}100 \\
316 \\
8 \cdot 4\end{array}$ & $\frac{100}{211}$ & $\begin{array}{l}100 \\
527 \\
7 \cdot 6\end{array}$ \\
\hline
\end{tabular}

\section{Discussion of the Warting List Problem}

The results discussed above and general experience gained in the course of the analysis lead to a number of organizational points concerning the management of waiting lists:

\section{STANDARDIZATION}

It is vital that waiting lists should be kept in standardized form - there is no room today for an esoteric system intelligible only to a particular consultant and his secretary. Lists for different hospitals should generally be kept separate and transfers from one list to another recorded as such.

\section{BOOKING INFORMATION}

The concept of a 'booked' case raises difficulties, as mentioned above. It would seem to be preferable to think in terms of giving dates to a large proportion of patients as soon as possible and recording the degree to which such dates are provisional, so that they can be changed or confirmed nearer the time of admission.

\section{Priority Rating}

Clinical priorities are, of course, inevitable, but there is a danger that low priority cases may be left indefinitely. Occasionally, one suspects, patients meet the same fate as unanswered letters-as time goes by they become steadily less likely to be seen to. To prevent this, a priority rating may be devised which is automatically increased as time elapses.

\section{REGULAR REVIEW}

Waiting list review is clearly necessary from time to time, to remove patients who no longer need or wish to be admitted. The task becomes less tedious and difficult if it is done regularly.

\section{SHORT-NOTICE LisTs}

While many patients need plenty of notice in order to fix their family arrangements, some do not. Those who are willing to remain on a short-notice list can be of material assistance to the smooth functioning of the hospital and they should arguably be rewarded by being given shorter average waiting times. It has been shown elsewhere (Bithell, 1969b) that the greatest benefit is obtained if patients with lengths of stay that are long and predictable are booked, while patients with shorter and more variable spells are put on a short-notice list.

These points are particularly important now that many hospitals are starting to contemplate the use of computers for the administration of their waiting lists and bed complements. The power of the computer operating a logically planned system can remove a lot of the anomalies associated with some waiting lists in the past.

\section{SUMmary}

The waiting lists at St. Thomas' Hospital are analysed using data from the 1965-6 In-patient Study. The emphasis is on the characteristics of the patients themselves rather than on the list sizes. Waiting times, for example, are examined and found to depend strongly on age, older patients being admitted more quickly. Proportions of patients failing to arrive when sent for are analysed by amount of notice, time on the waiting list, method of communication, etc. Booked cases are discussed, as are removals of patients from the lists. Some general conclusions about the organization of waiting lists are drawn.

I wish to thank the large number of people who were involved in the organization and analysis of the survey on which this article has drawn, especially G. J. Draper and J. M. Bevan who initiated and designed it. I am grateful to the Nuffield Foundation, the United Oxford Hospitals, and the Oxford Regional Hospital Board for financial support and to the Governors of St. Thomas' Hospital, London, for permission to publish the results. The latter have asked me to state that, following the Study, several points emerging have been taken account of in the re-organization of their waiting lists; but they do not necessarily accept all the views put forward in this article.

\section{REFERENCES}

BrtHell, J. F. (1968). St. Thomas' Hospital: Report on Admissions Study. Duplicated.

- (1969a). A survey of in-patients of a London teaching hospital: general results. Brit. J. prev. soc. Med., 23, 101.

(1969b). The statistics of hospital admission systems. Appl. Statist., 18, 119.

Grundy, F., Hitchins, R. A. N., and Lewis-FANING, E. (1956). A Study of Hospital Waiting Lists in Cardiff.

Ministry of Health and General Register Office (1968). Report on Hospital In-Patient Enquiry for the year 1966. H.M.S.O., London.

Morris, D., Hall, G. A., and HaNDYside, A. J. (1969). Admissions from surgical waiting lists. Brit. J. prev. soc. Med., 23, 233. 